\title{
STUDI KELAYAKAN PENGEMBANGAN USAHA PENGGEMUKAN SAPI POTONG DI KELURAHAN PLESUNGAN KECAMATAN GONDANGREJO KABUPATEN KARANGANYAR
}

\author{
Nur Cahyo Budi Prasongko ${ }^{1)}$, Kusnandar ${ }^{2)}$, Erlyna Wida Riptanti ${ }^{3)}$ \\ 1) Mahasiswa Program Studi Agribisnis Fakultas Pertanian UNS \\ 2) Dosen Pembimbing Utama \\ 3) Dosen Pembimbing Pendamping \\ Program Studi Agribisnis Fakultas Pertanian, Universitas Sebelas Maret Surakarta \\ Jl. Ir. Sutami No.36 A Kentingan Surakarta 57126 Telp./Fax (0271) 637457 \\ Email: nurcahyobudip@gmail.com
}

\begin{abstract}
The study aims to determine the feasibility of developing fattening beef cattle based on market aspects, technical aspects, management aspects, environmental aspects, financial aspects and business sensitivity. The basic method of research is descriptive case study technique. The research location is determined by deliberate on farms H. Wakimin Plesungan Village Gondangrejo District of Karanganyar Regency. The data used are primary data and secondary data. Data analysis market aspects, technical aspects, management aspects, and aspects of the environment carried out by descriptive method. While the financial aspects of data analysis using the eligibility criteria payback period, NPV, IRR, Net B/C, Gross B/C, and sensitivity analysis. The results showed: (1) the development of beef cattle fattening farm $\mathrm{H}$. Wakimin based on market aspects, technical aspects, management aspects and environmental aspects to be developed. (2) Analysis of the financial aspects of the show to be developed by the project life of 10 years with a discount rate of $12 \%$ and the inflation rate $5.14 \% / y e a r$. NPV of IDR 237,165,474.00, IRR 44.53\%, net B/C 2.83, Gross B/C of 1.06 and a PP for 2.91 years. (3) The sensitivity analysis shows the maximum limit of the target reduction Improved Weight Loss Daily (PBBH) of cattle of $16 \%$ or minimum PBBH $0.84 \mathrm{~kg} /$ day. While the maximum limit of feeder cattle prices increase by $11 \%$ or IDR 44.400.00 per kg of live weight of cattle assuming other costs are fixed.
\end{abstract}

Keywords: fattening beef cattle, feasibility studies, business sensitivity.

\begin{abstract}
Abstrak : Penelitian bertujuan untuk mengetahui kelayakan pengembangan usaha penggemukan sapi potong berdasarkan aspek pasar, aspek teknis, aspek manajemen, aspek lingkungan, aspek finansial dan sensitivitas usaha. Metode dasar penelitian adalah deskriptif dengan teknik studi kasus. Lokasi penelitian ditentukan secara sengaja di peternakan H. Wakimin Kelurahan Plesungan Kecamatan Gondangrejo Kabupaten Karanganyar. Data yang digunakan adalah data primer dan data sekunder. Analisis data aspek pasar, aspek teknis, aspek manajemen, dan aspek lingkungan dilakukan dengan metode deskriptif. Sedangkan analisis data aspek finansial menggunakan kriteria kelayakan Payback period, NPV, IRR, Net B/C, Gross B/C, dan analisis sensitivitas. Hasil penelitian menunjukan: (1) pengembangan usaha penggemukan sapi potong di peternakan $\mathrm{H}$. Wakimin berdasarkan aspek pasar, aspek teknis, aspek manajemen dan aspek lingkungan layak untuk dikembangkan. (2) Analisis aspek finansial menunjukkan layak untuk dikembangkan dengan umur proyek 10 tahun dengan tingkat discount rate 12\% dan tingkat inflasi 5,14\%/tahun. Nilai NPV sebesar Rp 237.165.474,00, nilai IRR 44,53\%, net B/C 2,83, Gross B/C sebesar 1,06 dan PP selama 2,91 tahun. (3) Analisis sensitivitas menunjukan batas maksimum penurunan target Peningkatan Berat Badan Harian (PBBH) sapi sebesar
\end{abstract}


$16 \%$ atau PBBH minimum $0,84 \mathrm{~kg} /$ hari. Sedangkan batas maksimum peningkatan harga bakalan sapi sebesar $11 \%$ atau $\mathrm{Rp} 44.400,00$ per kg berat hidup sapi dengan asumsi biaya yang lain bersifat tetap.

Kata kunci: penggemukan sapi potong, studi kelayakan, sensitivitas usaha.

\section{PENDAHULUAN}

Sapi potong merupakan komoditas subsektor peternakan yang sangat potensial di Indonesia. Hal tersebut dapat dilihat dari tingginya permintaan masyarakat akan daging sapi. Jumlah penduduk Indonesia menurut data Badan Pusat Statistik tahun 2013 sekitar 249,9 juta jiwa membutuhkan pasokan daging sapi untuk dikonsumsi dalam jumlah yang sangat besar. Sedangkan menurut data Kementrian Pertanian (2015) rata-rata konsumsi daging sapi segar masyarakat Indonesia pada tahun 2000 2014 sebesar 2,070 kg per kapita per tahun.

Sejauh ini peternakan domestik belum sepenuhnya mampu memenuhi permintaan daging sapi dalam negeri. Upaya pemenuhan kebutuhan daging sapi dilakukan pemerintah dengan melakukan impor daging sapi. Berdasarkan data Ditjennak (2015), volume impor daging sapi dari tahun 2011 - 2014 cenderung mengalami kenaikan dan produksi daging sapi dari dalam negeri pada tahun 2014 hanya mampu memenuhi $66,85 \%$ dari total kebutuhan daging dalam negeri.

Produksi daging sapi dalam negeri yang belum mampu memenuhi permintaan tersebut terkait dengan adanya berbagai permasalahan dalam pengembangan sapi potong. Beberapa permasalahan tersebut adalah: 1) usaha bakalan kurang diminati oleh pemilik modal karena secara ekonomis kurang menguntungkan dan dibutuhkan waktu pemeliharaan yang lama, 2) ketersediaan pakan tidak kontinu dan kualitasnya rendah terutama pada musim kemarau, 3) pemanfaatan limbah pertanian dan agroindustri pertanian sebagai bahan pakan belum optimal, serta 4) gangguan wabah penyakit (Suryana, 2009).

Provinsi Jawa Tengah merupakan salah satu provinsi dengan jumlah populasi sapi potong cukup besar. Namun dilihat dari segi produksi daging sapi, Provinsi Jawa Tengah masih rendah jika dibandingkan dengan Provinsi Jawa Barat. Salah satu kabupaten yang menyokong produksi daging sapi ialah
Kabupaten Karanganyar. Produksi daging sapi Kabupaten Karanganyar sebesar 1.989 ton pada tahun 2013 atau hanya 3,25\% dari total produksi (BPS Jawa Tengah, 2014).

Peternakan H. Wakimin terletak di Kampung Suluhrejo Rt 9 Rw 9 Kelurahan Plesungan Kecamatan Gondangrejo Kabupaten Karanganyar. Permintaan daging sapi yang terus meningkat mendorong $\mathrm{H}$. Wakimin untuk mengembangkan usahanya dengan menambah satu kandang lagi dengan kapasitas 30 ekor sapi setiap tahunya. Penambahan investasi ini memerlukan biaya yang cukup besar, sedangkan modal merupakan sumberdaya yang terbatas. Selain itu, usaha penggemukan sapi potong memiliki beberapa ketidakpastian yang memungkinkan terjadinya perubahanperubahan yang akan mempengaruhi kelayakan usaha seperti yang disampaikan dalam penelitian Yoga (2013) dan Reza (2014). Oleh sebab itu perlu dilakukan kajian studi kelayakan usaha untuk mempelajari secara mendalam tentang usaha penggemukan sapi potong yang akan dijalankan, dalam rangka menumbuhkan layak atau tidaknya suatu usaha tersebut dijalankan.

\section{METODE PENELITIAN}

Metode dasar penelitian menggunakan metode deskriptif dengan teknik studi kasus (Heru dan Totok, 2010). Penelitian dilaksanakan di peternakan H. Wakimin, Kampung Suluhrejo Rt 9 Rw 9, Kelurahan Plesungan, Kecamatan Gondangrejo, Kabupaten Karanganyar. Pemilihan lokasi dengan pertimbangan bahwa peternakan sudah berorientasi bisnis serta sering dijadikan sebagai lokasi Praktek Kerja Lapang (PKL) mahasiswa dari Akademi Peternakan Karanganyar.

Penentuan informan dalam penelitian dapat dilakukan secara purposive dengan pertimbangan-pertimbangan tertentu sesuai dengan tujuan penelitian (Bungin, 2011). Informan dalam penelitian ini antara lain $\mathrm{H}$. Wakimin sebagai pelaku usaha, pedagang sapi, 
petugas pasar hewan, Bank BRI Gondangrejo serta Dinas Peternakan dan Perikanan Kabupaten Karanganyar.

Data yang digunakan dalam penelitian terdiri dari data primer dan data sekunder. Teknik pengumpulan data yang digunakan dalam penelitian ini adalah wawancara, dokumentasi dan observasi.

Metode analisis data aspek pasar, aspek teknis, aspek manajemen, dan aspek lingkungan dilakukan dengan analisis deskriptif. Metode analisis kelayakan aspek finansial dilakukan dengan membuat arus kas (Cash flow) dan menganalisis dengan kriteria kelayakan investasi sebagai berikut:

1. Payback period

$$
\mathrm{PP}=\frac{\text { Investas } \mathrm{i}}{\text { Ka s bers ih } / \text { tahun }} \times 1 \text { thn.....(1) }
$$

Investasi dinyatakan layak jika PP lebih pendek dibandingkan dengan PP Maksimum. Jika sebaliknya maka investasi tidak layak.

2. Net Present Value (NPV)

$\mathrm{NPV}=\left(\frac{\text { Kas bers ih tahun } 1}{(1+\mathrm{r})^{1}}\right)+\cdots+$
$\left(\frac{\text { Kas Be rsih thn ke }-\mathrm{n}}{(1+\mathrm{r})^{\mathrm{n}}}\right)-$ Investasi...

Ket: NPV = Net Present Value

$\mathrm{n}=$ Tahun kegiatan bisnis

$\mathrm{r}=$ Tingkat suku bunga (\%).

Kriteria kelayakan: NPV > 0 maka investasi layak dijalankan. Jika nilai NPV $=0$ maka investasi berada pada titik impas. NPV $<0$, maka investasi tidak layak.

3. Internal Rate of Return (IRR)

$\mathrm{IRR}=i_{1}+\left[\frac{N P V_{1}}{N P V_{1}-N P V_{2}} x\left(i_{1}-i_{2}\right)\right]$.

Keterangan:

$\mathrm{IRR}=$ Tingkat pengembalian usaha

$\mathrm{NPV}_{1}=$ Nilai Net Present Value $(+) \mathrm{NPV}_{2}=$

Nilai Net Present Value (-)

i1 = Tingkat suku bunga NPV (+)

i2 = Tingkat suku bunga NPV (-)

Kriteria kelayakan: IRR > MARR maka investasi layak dijalankan. Jika IRR = MARR maka usaha dinyatakan tidak untung atau tidak rugi. IRR < MARR maka investasi tidak layak dijalankan.

4. Gross B/C

Gross B/C $=\frac{\sum \text { PV Total Benefit }}{\sum \text { PV Total Cost }} . . . . . .(4)$

Kriteria kelayakan: Gross B/C > 1 maka rencana investasi layak dijalankan. Gross $\mathrm{B} / \mathrm{C}=1$ maka usaha perluasan tidak layak diajalankan. Gross B/C $<1$ maka investasi tidak layak dijalankan.

5. Net $\mathrm{B} / \mathrm{C}$

Net $\mathrm{B} / \mathrm{C}=\frac{\sum \mathrm{PV}(\mathrm{B}-\mathrm{C}) \text { positif }}{\sum \mathrm{PV}(\mathrm{B}-\mathrm{C}) \text { ne gatif }}$

Kriteria kelayakan: $\mathrm{Net} B / C=1$, usaha tersebut tidak menguntungkan atau tidak merugikan. Net $B / C>1$, usaha tersebut layak untuk dijalankan. Net $B / C<1$, usaha tersebut tidak layak.

Analisis sensitivitas merupakan analisis yang ditujukan untuk mengetahui tingkat perubahan maksimum yang dapat terjadi pada komponen inflow maupun outflow agar suatu usaha tetap layak di usahakan. Analisis ini dilakukan dengan cara mengubah komponen tersebut secara coba-coba hingga diperoleh nilai perubahan maksimum yang dapat ditoleransi sehingga usaha masih layak dijalankan.

\section{HASIL DAN PEMBAHASAN}

\section{Aspek Pasar}

\section{Permintaan Sapi Potong}

Petumbuhan konsumsi daging sapi per kapita per tahun di Indonesia dari tahun 2000 - 2014 selalu meningkat. Rata-rata pertumbuhan konsumsi daging sapi oleh masyarakat sebesar 4,22\% per tahun dengan tingkat konsumsi 2,36 $\mathrm{kg} / \mathrm{kapita} /$ tahun pada tahun 2014 (Kementrian pertanian, 2015). Menurut Bank Indonesia (2013) elastisitas permintaan daging sapi terhadap pendapatan dan pertambahan penduduk relative tinggi $(>1)$. Oleh karenanya permintaaan daging sapi hampir tidak terpengaruh oleh kenaikan harga sapi.

Tingginya permintaan daging sapi menyebabkan ketidak seimbangan antara permintaan dan penawaran karena disisi produksi pada kenyataannya belum dapat mengimbangi. Produksi peternakan dalam negeri hanya mampu memasok $65,58 \%$ pada tahun 2014 dari total kebutuhan daging (Ditjennak 2015). Kekurangan kebutuhan daging tersebut dicukupi dengan melakukan impor daging.

Kondisi pemasaran sapi potong di Kabupaten Karanganyar sendiri juga masih terbuka. Hal tersebut dapat dilihat dari tingkat pertumbuhan pemotongan sapi potong yang jauh lebih tinggi dibandingkan dengan tingkat 
pertumbuhan populasinya. Tingkat pertumbuhan pemotongan sapi potong di Kabupaten Karanganyar sebesar $2,6 \%$ setiap tahunnya dan $-13,1 \%$ untuk pertumbuhan populasi sapi (BPS Kabupaten Karanganyar, 2014). Kecamatan Gondangrejo menjadi kecamatan dengan tingkat pemotongan sapi terbesar di Kabupaten Karanganyar, dimana sapi potong yang di potong pada Rumah Potong Hewan di Kecamatan Gondangrejo tercatat sebesar 3.732 ekor sapi pada tahun 2013. Tingginya pemotongan sapi tersebut salah satunya untuk memenuhi kebutuhan daging sapi di Kabupaten Karanganyar dan Kota Surakarta.

\section{Perdagangan Sapi Antar Daerah}

Perdagangan sapi antar daerah menunjukan dinamika pengeluaran dan pemasukan ternak yang terjadi di suatu wilayah. Berdasarkan kondisi tersebut, suatu wilayah dapat dikategorikan sebagai wilayah yang swasembada atau masih kekurangan sapi potong. Kondisi peternakan sapi potong di Provinsi Jawa Tengah dari tahun 2011 - 2015 masih dalam kategori kekurangan sapi potong/defisit. Data perkiraan tahun 2015 Provinsi Jawa Tengah akan memasukan sapi potong sebesar 10.539 ekor (Ditjennak 2015).

Rencana pengembangan usaha penggemukan sapi potong di peternakan $\mathrm{H}$. Wakimin sangat strategis. Hal tersebut dapat dilihat dari dekatnya lokasi dengan wilayah wilayah di Solo Raya yang masih kekurangan sapi potong seperti wilayah Sragen, Boyolali, dan Wonogiri. Selain itu, lokasi rencana penggembangan usaha juga dekat dengan kota Surakarta, dimana kebutuhan akan daging sapi di kota Surakarta akan jauh lebih besar. Secara umum rencana pengembangan usaha penggemukan sapi potong di peternakan $\mathrm{H}$. Wakimin layak secara aspek pasar. Hal tersebut dilihat dari peluang-peluang pasar yang telah diuraikan di atas

\section{Aspek Teknis \\ Kesesuaian Lokasi Usaha}

Lokasi usaha yang akan dibangun kandang sudah dekat dengan pasar yang dituju. Sehingga kegiatan transportasi penjualan sapi ataupun pengadaan bakalan sapi dan pakan bisa lebih efisien. Pasar yang dituju antara lain pasar hewan Purworejo, Sragen, Karangpandan, Bekonang dan RPH Kecamatan Gondangrejo.
Pencarian tenaga kerja dilokasi usaha relatif lebih mudah karena banyak tenaga kerja yang tesedia dan mayoritas berprofesi sebagai petani. Ketersediaan instalasi listrik dan air disekitar lokasi usaha sudah mudah dijangkau.

$$
\text { Kondisi iklim disekitar wilayah }
$$

peternakan berkisar $23-32{ }^{\circ} \mathrm{C}$. Kondisi tersebut sudah sesuai untuk menunjang perkembangan ternak sapi Brahman yang akan digemukkan. Sapi Brahman dapat beradaptasi dengan baik pada lingkungan yang cukup panas seperti di lingkungan rencana penggemukan (Agriflo 2012; Blackshaw (1994); Beatty et al (2006). Lokasi usaha tersebut juga cukup jauh dari pemukiman warga sehingga tidak mengganggu aktifitas warga sekitar.

\section{Perkandangan}

Tipe kandang yang direncanakan $\mathrm{H}$. Wakimin dengan sistem ternak sapi saling membelakangi. Sistem kandang ini lebih efisien dalam mengumpulkan kotoran sapi. Luas kandang yang akan di bangun sebesar $15 \mathrm{~m} \mathrm{x} 19 \mathrm{~m}$ atau per individu sapi memperoleh luas $2 \mathrm{~m}$ x 2,5 m. Lantai kandang dibuat dari semen dengan tingkat kemiringan lantai $\pm 2 \%$ dan tebal minimum $5 \mathrm{~cm}$. Kemiringan lantai ditujukan agar limbah cair dapat mengalir ke pembuangan. Diujung kandang terdapat Instalasi Pengolahan Air Limbah (IPAL) yang dapat menanggulangi dampak pencemaran kotoran cair ternak ke lingkungan. Dinding kandang dibuat setengah sampai tinggi kotak pakan. Dinding tersebut difungsikan untuk memperlancar sirkulasi udara sehingga kondisi di kandang lebih sejuk.

Atap kandang menggunakan genting. Tinggi bangunan kandang yang direncanakan setinggi $4 \mathrm{~m}$. Atap yang tinggi juga difungsikan untuk menjaga kondisi udara di dalam kandang agar lebih sejuk. Lay out perkandangan yang direncanakan dapat dilihat pada Gambar 1.

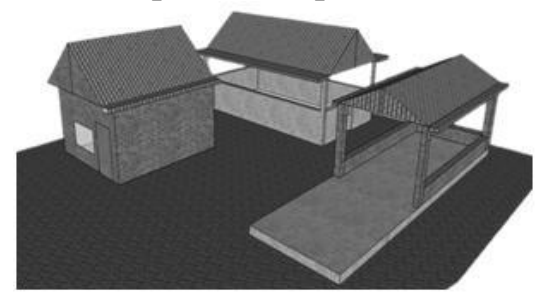

Gambar 1. Lay Out Perkandangan Rencana Penggemukan Sapi Potong di Peternakan H. Wakimin. 
Nur Cahyo B. P., Kusnandar, Erlyna W. R. : Studi Kelayakan Pengembangan Usaha...

Tabel 1. Komposisi Pakan untuk Proses Penggemukan Sapi/ekor.

\begin{tabular}{|c|c|c|c|c|c|c|}
\hline \multirow[b]{2}{*}{ Jenis Pakan } & \multicolumn{2}{|c|}{$\begin{array}{c}\text { Berat Sapi 300-350 kg } \\
\text { (Bulan ke } 1 \text { dan 2) }\end{array}$} & \multicolumn{2}{|c|}{$\begin{array}{c}\text { Berat Sapi 350-400 kg } \\
\text { (Bulan ke } 3 \text { dan 4) }\end{array}$} & \multicolumn{2}{|c|}{$\begin{array}{c}\text { Berat Sapi }>400 \mathrm{~kg} \\
(\text { Bulan ke } 5 \text { dan 6) }\end{array}$} \\
\hline & Per-hari & Per-bulan & Per-hari & Per-bulan & Per-hari & Per-bulan \\
\hline \multicolumn{7}{|l|}{ Jerami } \\
\hline Fermentasi & 2 & 60 & 2 & 60 & 2 & 60 \\
\hline Rumput gajah & 11 & 330 & 11 & 330 & 11 & 330 \\
\hline Ampas tahu & 5 & 150 & 10 & 300 & 10 & 300 \\
\hline Pollard & 1,5 & 45 & 1 & 30 & 2 & 60 \\
\hline Dedak padi & 3 & 90 & 2,5 & 75 & 2,5 & 75 \\
\hline Garam & 0,1 & 3 & 0,1 & 3 & 0,1 & 3 \\
\hline Promix & 0,01 & 0,3 & 0,01 & 0,3 & 0,01 & 0,3 \\
\hline
\end{tabular}

\section{Pengadaan dan Pemilihan Bakalan}

Kriteria pemilihan bakalan yang baik menurut H. Wakimin sebagai berikut; Jenis bakalan yang dipilih adalah sapi jantan jenis Brahman yang berjumlah 30 ekor setiap tahunya atau 15 ekor setiap periode penggemukan. Bakalan yang dipilih tidak gemuk, proporsional dan sehat. Bakalan berumur kira-kira 2,5 sampai 3 tahun karena memiliki laju pertumbuhan yang optimal. Berat bakalan awal diperkirakan ratarata $300 \mathrm{~kg}$.

Kondisi bakalan sapi Brahman di pasar hewan cukup banyak dan tersedia. Misalnya di pasar hewan Purworejo Kaliyoso, jumlah bakalan sapi Brahman di pasar tersebut berkisar antara 20 ekor setiap kegiatan pasaran. Bakalan sapi yang berkualitas seperti sapi Brahman, Simental, Limmousin dan jenis lainya tentunya akan semakin tersedia di pasar peternakan sapi di berbagai daerah seperti Karanganyar. Hal tersebut didukung dengan adanya pengembangan teknologi di bidang reproduksi peternakan yakni adanya Inseminasi Buatan (IB).

\section{Manajemen Pakan}

Produktivitas ternak dipengaruhi oleh faktor genetik (30\%) dan lingkungan $(70 \%)$. Pengaruh faktor lingkungan antara lain pakan, teknik pemeliharaan, kesehatan, dan iklim. Pakan mempunyai pengaruh yang paling besar (60\%) dibandaing faktor lingkungan lainya (Edy dan Endang, 2010). Besarnya pengaruh pakan ini membuktikan bahwa produksi ternak yang tinggi tidak dapat tercapai tanpa adanya pemberian pakan yang sesuai baik secara kualitas dan kuantitas. Berdasarkan perhitungan pakan yang di lakukan, kebutuhan pakan sapi per ekor selama proses penggemukan secara ringkas dapat dilihat dalam Tabel 1.

Hasil perhitungan pakan dalam Tabel 1 tidak jauh berbeda dengan komposisi pakan yang digunakan dalam penelitian Maman dan Sidik (2003) serta Mirni et al (2014). Sehingga komposisi pakan sudah baik. Kebutuhan pakan sapi untuk proses penggemukan setiap bulanya semakin meningkat. Hal tersebut ditujukan untuk memasok kebutuhan energi/TDN sapi dalam proses penggemukan yang semakin meningkat pula. Disisi lain, sapi memiliki keterbatasan dalam mengkonsumsi bahan pakan yang disediakan. Semakin besar sapi yang digemukan, maka kemampuan mengkonsumsi pakannya dalam bentuk bahan kering akan semakin rendah juga. Oleh sebab itu perlu perhitungan yang baik untuk menyusun bahan pakan untuk proses penggemukan sapi. Penggunaan pakan hijauan dan limbah agroindustri tersebut dapat memperkuat ketahanan pakan sapi (Kariyasa, 2005; Mayulu et al, 2009). Peningkatan pakan terbesar dalam perhitungan terjadi pada pakan ampas tahu, karena ampas tahu memiliki kandungan energi/TDN terbesar $(79 \%)$ dengan kadar bahan kering sebesar $26,2 \%$.

Pemberian konsentrat dan hijauan diatur berdasarkan tingkat kecernaan pakan yang lebih tinggi, sebab pemberian hijauan yang hampir bersamaan waktunya dengan pemberian konsentrat akan berakibat pada penurunan 
kecernaan bahan kering pakan, karena rumen sapi memiliki preferensi mencerna pakan konsentrat terlebih dahulu (Sori 2003; Ayu et al 2015). Jadwal pemberian pakan dapat dilihat dalam Gambar 2.

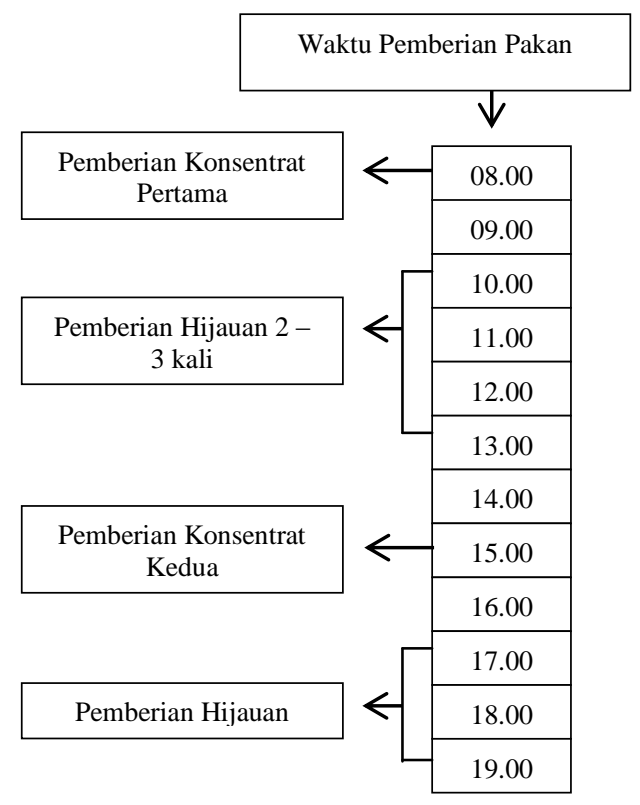

Gambar 2. Jadwal Pemberian Pakan

\section{Pembersihan Kandang}

Kegiatan pembersihan kandang dan tempat pakan maupun minum dilakukan pada pagi hari dan sore hari. Sanitasi kandang tersebut dapat membantu kenyamanan sapi didalam kandang sehingga proses penggemukan sapi dapat berjalan dengan baik dan sapi terhindar dari penyakit.

\section{Proses Pengolahan Limbah}

Pembuatan pupuk kandang di peternakan $\mathrm{H}$. Wakimin dilakukan dengan sistem terbuka. Prinsip pembuatan pupuk kandang dengan secara terbuka adalah adanya kontak dengan udara bebas ketika proses de-komposisi terjadi. Proses dekomposisi pada sistem terbuka dapat berlangsung lebih cepat dibandingkan dengan sistem tertutup.

Tahap pembuatan pupuk kandang secara terbuka sebagai berikut; menjemur kotoran sapi yang telah terkumpul di tempat terbuka selama 2 sampai 3 hari. Penjemuran dapat dilakukan di lantai beton di dekat lokasi tempat limbah. Setelah dijemur, dilakukan penimbunan kotoran sapi di tempat beratap. Tempat penimbunan yang digunakan untuk penimbunan tidak berdinding sehingga hembusan angin bisa leluasa keluar masuk. Dengan demikian, proses dekomposisi akan berjalan lebih cepat. Setelah 2 minggu dalam penimbunan, biasanya kotoran telah matang dan siap untuk dikemas. Pupuk kandang dikemas dengan berat $50 \mathrm{~kg} / \mathrm{karung}$ dan siap untuk dijual. Berdasarkan uraianuraian di atas pengembangan usaha penggemukan sapi potong di peternakan $\mathrm{H}$. Wakimin secara teknis layak untuk dijalankan.

\section{Aspek Manajemen}

Analisis aspek manajemen ditujukan untuk menganalisis fungsi-fungsi manajmen seperti pelaksanaan fungsi perencanaan, pengorganisasian, pelaksanaan dan pengendalian (Plant, Organising, Action and Controling/ POAC) pada rencana pengembangan usaha penggemukan sapi potong di peternakan H. Wakimin. Kegiatan manajemen perencanaan produksi yang paling penting ialah menentukan jadwal penggemukan sapi. Jadwal penggemukan sapi akan berpengaruh pada kapan sapi akan dibeli dan kapan sapi akan dijual. Harga sapi yang berfluktuasi setiap tahunya harus dijadikan pertimbangan untuk memilih waktu yang tepat. Berdasarkan pendugaan perilaku fluktuasi harga sapi setiap tahunya menurut Sasongko dan Farida (2012), alternatif jadwal yang paling baik dilakukan berdasarkan skema 6 . Penggemukan periode pertama dilakukan pembelian sapi pada bulan ke 6, dimana harga sapi sedang turun karena bertepatan dengan musim tanam dan tahun ajaran baru sekolah. Penjualan sapi periode pertama diperkirakan pada bulan ke 11, pada bulan-bulan tersebut mendekati waktu panen petani dan berdekatan pada hari besar yaitu Idul Adha. Periode ke dua dilakukan pembelian sapi pada bulan ke 12, harga sapi pada bulan tersebut diperkirakan turun dari harga normal karena bertepatan dengan musim tanam pertanian (labuhan). Penggemukan sapi periode kedua diperkirakan dijual pada bulan ke 5, dimana harga sapi diperkirakan masih pada kisaran harga normal.

Aspek menajemen selanjuatnya berkaitan dengan perencanaan sumber daya manusia (SDM). Perencanaan SDM merupakan suatu kegiatan yang dilakukan secara sistematis untuk meramalkan atau memperkirakan kebutuhan sumber daya manusia yang dibutuhkan dalam suatu bisnis. H. Wakimin memperkirakan jumlah tenaga kerja yang dibutuhkan untuk 
pengembangan usaha penggemukan sapi potong sebanyak 2 orang. Tenaga kerja dapat diperoleh dari warga sekitar dengan kriteria rajin, ulet dan sayang terhadap binatang atau sapi. $\mathrm{H}$. Wakimin tidak mempermasalhakan jenjang pendidikan karena, aplikasi pekerjaan dalam usaha penggemukan relatif sederhana.

Fungsi pengorganisasian dan pelaksanaan yaitu mengkoordinasikan setiap fungsi dan tugas kepada pekerjanya. Hal ini dilakukan agar pekerjaan dapat berjalan dengan baik dan terintegrasi. Susunan organisasi yang diterapkan masih sederhana, karena skala usaha yang dilakukan masih kecil. Sehingga pimpinan usaha dipegang oleh $\mathrm{H}$. Wakimin sendiri dan selanjutnya anak kandang diisi oleh dua tenaga kerja perawat ternak. Hasil analisis aspek manajamen di peternakan $\mathrm{H}$. Wakimin dinilai layak untuk mengelola satu kandang baru lagi dengan jumlah ternak 30 ekor/tahun. Hal tersebut didukung dari pengalaman $\mathrm{H}$. Wakimin yang sudah mengelola peternakan dari tahun 1993 hingga sekarang dan kemampuan memimpin dalam usaha penggemukan sapi potong yang dijalankannya.

\section{Aspek Lingkungan \\ Kondisi lingkungan disekitar usaha}

Rencana pengembangan usaha penggemukan sapi potong di peternakan $\mathrm{H}$. Wakimin berada pada kampung Suluhrejo Rt 09 Rw 09 kelurahan Plesungan. Kondisi lingkungan disekitar lokasi masih asri seperti pedesaan dengan lahan pertanian yang cukup luas. Disamping itu, disekitar lokasi masih banyak tanaman Jati maupun Mahoni milik warga yang ditanam dipekarangan-pekarangan rumah. Di areal lokasi juga terdapat satu kandang peternakan ayam potong. Oleh sebab itu, lokasi tersebut sangat sesuai untuk penggemukan sapi potong.

\section{Dampak positif}

Usaha penggemukan sapi potong membantu meningkatkan ketersediaan daging sapi yang selama ini masih kurang di pasar. Selain itu, usaha ini mampu menyerap limbah industri seperti ampas tahu maupun limbah pertanian seperti jerami sebagai bahan baku pakan ternak. Selama ini, limbah pertanian khususnya jerami masih sangat melimpah tersedia di wilayah Kabupaten Karanganyar dan Sragen maupun daerah-daerah Solo raya lainya. Kotoran sapi yang diolah menjadi pupuk dapat berfungsi memperbaiki struktur tanah dan meningkatkan kandungan hara. Sehingga petani disekitar lokasi usaha dapat dengan mudah mendapatkan pupuk untuk kegiatan produksi pertanianya. Disisi lain, adanya pengembangan usaha penggemukan sapi potong di peternakan $\mathrm{H}$. Wakimin tentu akan membuka lapangan kerja baru bagi warga sekitar.

\section{Dampak negatif}

Pengaruh negatif yang akan muncul di lokasi penggemukan sapi potong ialah adanya polusi udara yang disebabkan oleh bau kotoran sapi. Disisi lain, adanaya pemungutan jerami dari lahan pertanian sebagai sumber pakan apabila tidak diimbangi dengan pengembalian berupa pupuk kandang dari peternakan sapi dapat berpeluang menyebabkan kerusakan lingkungan pertanian.

\section{Upaya penanggulangan dampak negatif}

Upaya yang dilakukan untuk menanggulangi dampak negatif dari usaha penggemukan sapi potong diantaranya; meberikan Starbio dalam pengolahan kotoran ternak sapi sehingga bau yang ditimbulkan dapat diminalisir. Disisi lain, masyarakat sekitar tidak merasa terganggu terhadap keberadaan usaha penggemukan sapi potong di peternakan H. Wakimin. Lokasi kandang yang jaraknya cukup jauh dengan pemukiman dapat meminimalisir pencemaran udara. Berdasarkan analisis aspek lingkungan terhadap rencana pengembangan usaha penggemukan sapi potong di peternakan $\mathrm{H}$. Wakimin ini layak untuk dijalankan

\section{Aspek Finansial}

Analisis finansial dilakukan dengan menggunakan kriteria kelayakan finansial meliputi; NPV, IRR, Gross B/C, Net B/C dan Payback Periode (PP). Analisis finansial ini untuk megetahui besar manfaat yang diterima dan biaya yang dikeluarkan selama proyek tersebut dijalankan. Biaya yang dikeluarkan salah satunya ialah biaya investasi yang disajikan dalam Tabel 3. 
Nur Cahyo B. P., Kusnandar, Erlyna W. R. : Studi Kelayakan Pengembangan Usaha...

Tabel 3. Biaya Investasi

\begin{tabular}{clr}
\hline No & \multicolumn{1}{c}{ Uraian } & Biaya/Thn (Rp) \\
\hline 1 & Bakalan & 360.000 .000 \\
2 & Pakan & \\
& a. Jerami fermentasi & 5.400 .000 \\
& b.Rumput gajah & 17.820 .000 \\
& c. Ampas tahu & 45.000 .000 \\
& d.Pollard & 24.300 .000 \\
& e. Dedak padi & 36.000 .000 \\
& f. Garam & 540 \\
& g. Promix & 918 \\
3 & Obat-obatan & 700 \\
4 & Karung bekas & 1.296 .000 \\
5 & Rekening Listrik \& Telepon & 840 \\
6 & Pemeliharaan & 6.000 .000 \\
7 & Transportasi & $\mathbf{5 0 1 . 4 7 2 . 0 0 0}$ \\
\hline & Jumlah &
\end{tabular}

Tabel 4. Biaya Variabel/Tahun.

\begin{tabular}{clr}
\hline No & \multicolumn{1}{c}{ Uraian } & Total Harga $($ Rp) \\
\hline 1 & Tanah & 64.000 .000 \\
2 & Kandang & 35.000 .000 \\
3 & Gudang & 13.000 .000 \\
4 & Tempat Limbah & 7.000 .000 \\
5 & IPAL Kotoran Cair & 2.500 .000 \\
6 & Pemasangan Listrik & 2.000 .000 \\
7 & Instalasi Listrik & 500 \\
8 & Instalasi Air & 3.000 .000 \\
9 & Pompa Air & 500 \\
10 & Skop & 200 \\
11 & Timbangan & 500 \\
12 & Arco & 800 \\
13 & Ember & 300 \\
14 & Sabit & 80 \\
15 & Selang & 125 \\
\hline Jumlah Biaya Investasi & $\mathbf{1 2 9 . 5 0 5 . 0 0 0}$ \\
\hline
\end{tabular}

Biaya operasional yang dikeluarkan meliputi biaya tetap dan biaya variabel. Biaya Tetap digunkan untuk membayar tenaga kerja, Pajak Bumi Bangunan dan penyusutan peralatan setiap tahunya sebesar Rp 34.898.333,00. Biaya variabel yang dikeluarkan setiap tahunya dapat dilihat dalam Tabel 4.

Total biaya operasional/tahun sebesar $\mathrm{Rp}$ 536.370,333,00. Sedangkan penerimaan usaha dari penjualan sapi dan pupuk kandang sebesar Rp. 588.960.000,00. Sehingga total keuntungan yang diperoleh dari rencana pengembangan usaha sebesar Rp. 52.589.666,67. Hasil analisis kriteria kelayakan finansial pengembangan usaha penggemukan sapi potong dapat dilihat pada Tabel 5.

Hasil analisis finansial yang dilakukan berdasarkan kriteria-kriteria kelayakan yang di tentukan, rancana penggembangan usaha penggemukan sapi potong di peternakan $\mathrm{H}$. Wakimin layak untuk dijalankan.

\section{Analisis Sensitivitas Usaha \\ Sensitivitas Peningkatan Berat Badan Harian (PBBH) sapi}

Peningkatan berat badan harian sapi merupakan faktor penentu dari nilai penjualan sapi. Sekenario sensitivitas ditujukan pada penurunan target PBBH harian sapi yang telah ditetapkan, untuk komponen lainnya bersifat tetap. Hasil Analisis menunjukan bahwa penurunan target PBBH sapi maksimun sebesar $16 \%$ atau minimal PBBH sapi sebesar $0,84 \mathrm{~kg} / \mathrm{hari}$ masih layak untuk diusahakan.

Apabila penurunan target $\mathrm{PBBH}$ lebih dari $16 \%$ maka rencana pengembangan usaha tidak layak dijalankan.

\section{Sensitivitas pada peningkatan harga bakalan sapi.}

Biaya yang dikeluarkan dalam usaha penggemukan sapi potong yang paling besar adalah biaya pengadaan bakalan sapi. Analisis sensitivitas kedua ini digunakan untuk menganalisis berapa peningkatan biaya maksimum yang boleh terjadi pada pengadaan sapi bakalan. Hasil Analisis menunjukan bahwa peningkatan harga bakalan sapi maksimum sebesar $11 \%$ atau Rp 44.400,00 setiap kg berat hidup sapi. Apabila peningkatan harga bakalan sapi lebih besar dari $11 \%$ maka rencana pengembangan usaha tidak layak dijalankan dengan asumsi seluruh biaya lainya bersifat tetap. Harga bakalan sapi yang ditetapkan ialah Rp 40.000,00/kg berat hidup sapi. 
Nur Cahyo B. P., Kusnandar, Erlyna W. R. : Studi Kelayakan Pengembangan Usaha...

Tabel 5. Proyeksi Cash Flow Rencana Pengembangan Usaha Penggemukan Sapi Potong.

\begin{tabular}{|c|c|c|c|c|c|c|c|c|c|c|c|}
\hline \multirow[b]{2}{*}{ Uraian } & \multicolumn{11}{|c|}{ Tahun } \\
\hline & 0 & 1 & 2 & 3 & 4 & 5 & 6 & 7 & 8 & 9 & 10 \\
\hline \multicolumn{12}{|l|}{ Inflow } \\
\hline a. Penjualan Sapi & 0 & 576.000 .000 & 605.617 .920 & 636.758 .793 & 669.500 .931 & 703.926 .668 & 740.122 .578 & 778.179 .681 & 818.193 .680 & 860.265 .199 & 904.500 .035 \\
\hline c. Nilai Sisa & 0 & 0 & 0 & 0 & 0 & 0 & 0 & 0 & 0 & 0 & 1.000 .000 \\
\hline Total Inflow & 0 & 588.960 .000 & 619.244 .323 & 651.085 .866 & 684.564 .702 & 719.765 .018 & 756.775 .336 & 795.688 .724 & 836.603 .038 & 879.621 .166 & 925.851 .286 \\
\hline \multicolumn{12}{|l|}{ Outflow } \\
\hline \multicolumn{12}{|l|}{ b. Biaya Operasional } \\
\hline Biaya Tetap & 0 & 34.898 .333 & 36.380 .772 & 37.939 .438 & 39.578 .250 & 41.301 .330 & 43.113 .010 & 45.017 .848 & 47.020 .632 & 49.126 .399 & 51.340 .444 \\
\hline Biaya Variabel & 0 & 501.472 .000 & 527.257 .690 & 554.369 .281 & 582.874 .949 & 612.846 .379 & 644.358 .940 & 677.491 .876 & 712.328 .509 & 748.956 .441 & 787.467 .781 \\
\hline Total B.Oprsl & 0 & 536.370 .333 & 563.638 .462 & 592.308 .718 & 622.453 .199 & 654.147 .709 & 687.471 .950 & 722.509 .724 & 759.349 .140 & 798.082 .839 & 838.808 .225 \\
\hline Total Outflow & 129.505 .000 & 536.370 .333 & 563.638 .462 & 592.308 .718 & 622.453 .199 & 654.147 .709 & 687.471 .950 & 722.509 .724 & 759.349 .140 & 798.082 .839 & 838.808 .225 \\
\hline PV Total Outflow & 129.505 .000 & 478.902 .083 & 449.329 .131 & 421.593 .646 & 395.580 .261 & 371.180.977 & 348.294 .685 & 326.826 .707 & 306.688 .382 & 287.796 .673 & 270.073 .799 \\
\hline PV Benefit & (129.505.000) & 46.955 .060 & 44.328 .652 & 41.836 .413 & 39.472 .983 & 37.233 .024 & 35.111 .252 & 33.102 .463 & 31.201 .553 & 29.403 .538 & 28.025 .536 \\
\hline PV B Komulatif & $(129.505 .000)$ & (82.549.940) & $(38.221 .289)$ & 3.615 .125 & 43.088.107 & 80.321 .131 & 115.432 .383 & 148.534 .846 & 179.736 .400 & 209.139 .938 & 237.165 .474 \\
\hline \multirow{4}{*}{ Keterangan } & $\mathrm{NPV}=$ & 237.165.474 & Investasi Layak & & & & & & & & \\
\hline & Gross $\mathrm{B} / \mathrm{C}=$ & 1,06 & Investasi Layak & & & & & & & & \\
\hline & Net $B / C=$ & 2,83 & Investasi Layak & & & & & & & & \\
\hline & $\mathrm{PP}=$ & 2,91 Tahun & Investasi Layak & & & & & & & & \\
\hline
\end{tabular}

\section{KESIMPULAN DAN SARAN}

Hasil penelitian menunjukan bahwa pengembangan usaha penggemukan sapi potong di peternakan $\mathrm{H}$. Wakimin berdasarkan aspek pasar, aspek teknis, aspek manajemen, aspek lingkungan dan aspek finansial layak untuk dikembangkan. Nilai NPV diperoleh sebesar Rp 237.165.474,00, nilai IRR 44,53\%, net B/C 2,83, Gross B/C sebesar 1,06 dan payback period selama 2,91 tahun. Analisis sensitivitas menunjukan peningkatan harga bakalan lebih sensitif terhadap kelayakan usaha yakni maksimum peningkatan harga bakalan sapi sebesar $11 \%$ atau $\mathrm{Rp} 44.400,00$ per $\mathrm{kg}$ berat hidup sapi, apabila melebihi $11 \%$ maka usaha tidak layak dikembangkan dengan asumsi biaya yang lain bersifat tetap.

Hal yang dapat disarankan yaitu: (1) Pemilihan bakalan sapi yang akan digemukkan harus diperhatikan sebaik mungkin, karena biaya pengadaan bakalan merupakan biaya terbesar dalam usaha penggemukan serta tingkat pertambahan berat badan harian (PBBH) ditentukan dari bakalan yang baik. Selain itu, perubahan harga bakalan lebih sensitif terhadap kelayakan usaha penggemukan sapi potong, sehingga perlu diperhatikan waktu yang tepat untuk pembelian bakalan sapi potong. (2) Penggunaan pakan dan teknik pemberian pakan harus lebih diperhatikan untuk meningkatkan efisiensi penggunaan pakan dalam usaha penggemukan sapi potong, karena pakan merupakan bagian dari komponen biaya terbesar kedua setelah biaya pembelian bakalan. Semakin baik manajemen pakan yang diterapkan maka semakin layak usaha penggemukan sapi potong yang akan dilakukan.

\section{DAFTAR PUSTAKA}

Agriflo 2012. Sapi Dari Hulu ke Hilir dan Info Mancanegara. Penebar Swadaya Grup: Jakarta.

Ayu Astuti, Erwanto, Purnama Edy Santosa 2015. Pengaruh Cara Pemberian Konsentrat-Hijauan Terhadap Respon Fisiologis dan Performa Sapi Peranakan Simmental. Jurnal Ilmiah Peternakan Terpadu. Vol 3 (4).

Beatty, D.T., Barnes, A., Taylor, E., Pethick, D.W., McCarthy, M and Maloney, S.K 2006. Physiological responses of Bos Taurus and Bos Indicus cattle to prolonged, continuous heat and humidity. Journal Anim Sci. Vol. 84 Page: 72-85.

Blackshaw, J.K and Blackshaw, A.W 1994. Heat stress in cattle and the effect of shade on production and behaviour: a review. Australian Journal of 
Nur Cahyo B. P., Kusnandar, Erlyna W. R. : Studi Kelayakan Pengembangan Usaha...

Experimental Agriculture, Vol. 34 Page: 85-95.

Bank Indonesia 2013. Pola Pembiayaan Usaha Kecil Menengah Usaha Penggemukan Sapi Potong. Departemen Pengembangan Akses Keuangan dan UMKM BI: Jakarta.

Badan Pusat Statistik Jawa Tengah 2014. Jawa Tengah Dalam Angka Tahun 2014. http://jateng.bps.go.id. Diakses Pada 30 Maret 2016.

Badan Pusat Statistik Kabupaten Karanganyar 2014. Kabupaten Karanganyar Dalam Angka Tahun 2014. http://karanganyarkab.bps.go.id. Diakses Pada 30 Juni 2016.

Bungin Burhan 2011. Penelitian Kualitatif. Kencana: Jakarta.

Ditjennak 2015. Statistik Peternakan dan Kesehatan Hewan. http://ditjennak.pertanian.go.id. Diakses Pada 31 Desember 2015.

Edy Rianto dan Endang Purbowati 2010. Panduan Lengkap Sapi Potong. Penebar Swadaya: Jakarta.

Heru Irianto dan Totok Mardikanto 2010. Metoda Penelitian dan Evaluasi Agribisnis. Jurusan Agribisnis UNS: Surakarta.

Kariyasa, K. 2005. Sistem integrasi tanamanternak dalam perspektif reorientasi kebijakan subsidi pupuk dan peningkatan pendapatan petani. Jurnal Analisis Kebijakan Pertanian. Vol 3(1): 68-80
Kementrian Pertanian 2015. Outlook Komoditas Pertanian Sub Sektor Peternakan Daging Sapi. Pusat Data dan Sistem Informasi Pertanian Sekretaian Jendral Kementrian Pertanian: Jakarta.

Maman Suparman dan H. Muh. Sidik Aziz 2003. Formulasi Pakan Murah yang Berkualitas Untuk Usaha Penggemukan Sapi Bali. Hal 6 - 13. Prosiding Temu Teknis Fungsional Non Peneliti. Balai Pengkajian Teknologi Pertanian Sulawesi Selatan

Mayulu, Suryanto, Sunarso, Christiyanto, Ballo dan Refa'i 2009. Kelayakan Penggunaan Complete Feed Berbasis Jerami Padi Amofer Pada Peternakan Sapi Potong. Jurnal Indon Trop Anim Agric. Vol 34 (1).

Mirni Lamid, Tri Nurhajati, Retno Sri Wahjuni 2014. Potensi Konsentrat Plus untuk Penggemukan Sapi Potong di Kelompok Ternak Harapan Mulya dan Kelompok Tani Ternak Jaya Mulya di Kabupaten Bangkalan Madura. Jurnal Agroveteriner. Vol 3 (1).

Sasongko W.R., dan Farida Sukmawati M, 2012. Fluktuasi Harga Sapi.http://ntb.litbang.pertanian.go.id. Diakses pada 25 Mei 2016.

Sori Basya Siregar 2003. Penggemukan Sapi. Penebar Swadaya: Jakarta.

Suryana 2009. Pengembangan Usaha Ternak Sapi Potong Berorientasi Agribisnis Dengan Pola Kemitraan. Jurnal Litbang Pertanian. Vol. $28 \quad$ (1). 